\begin{tabular}{|c|c|}
\hline \multirow{3}{*}{ 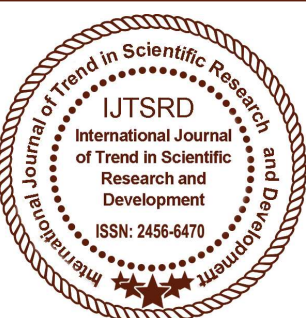 } & $\begin{array}{l}\text { International Journal of Trend in Scientific } \\
\text { Research and Development (IJTSRD) }\end{array}$ \\
\hline & International 0 \\
\hline & ISSN No: 2456 - 6470 | www.ijtsrd.com | Volume - 2 | Issue - 5 \\
\hline
\end{tabular}

\title{
A Study on Mechanical Properties of E-Glass Polypropylene Epoxy and S-Glass Polypropylene Epoxy Composites \\ Karthik A. $\mathbf{S}^{1}$, Dr. S. V. Gorabal ${ }^{2}$ \\ ${ }^{1}$ Assistant Professor, ${ }^{2}$ Principal \\ ${ }^{1}$ Smt Kamala and Sri Venkappa M. Agadi College of Engineering \& Technology, Laxmeshwar, Karnataka \\ ${ }^{2}$ Visvesvaraya Technological University, Belgaum, Karnataka, India
}

\section{ABSTRACT}

There are basic two phase of composite material, in which one is known as matrix material and another one is called reinforcing material. The reinforcing material is embedded over matrix material. The matrix material is continuous phase and reinforcing is discontinuous phase. The reinforcing phase is much harder than matrix phase. In composite material matrix phase removes the stresses between reinforcing phase and also protect from mechanical and environmental damage. The function of reinforcing material is to improve mechanical and thermal properties of composites. Composite are hybrid of two or more material such as reinforced polymer, metal or ceramics. The aim of the present work is to fabricate E-glass epoxy composite and S-glass epoxy composite with polypropylene as filler material. The fabricated laminates are then tested for mechanical properties with varying percentage of filler material. The results obtained for E-glass epoxy composite and S-glass epoxy composites are then compared. The composites with optimum results are recommended.

Keywords: E-glass, S-glass, Polypropylene, Impact strength

\section{INTRODUCTION}

\section{A. Matrix Material}

A variety of matrix polymer, metal, alloy, inter metallic, ceramics, carbon, cement etc. have been used for making composites. The matrix material serves several functions which are vital to the performance of the composite material. These functions also depend upon the type of reinforcement such as dispersions, particulates, whispers, discontinuous or continuous fibers. The matrix enables the composite to withstand compression, flexural and shear forces or tensile loads. The polymer material for a matrix can be thermosetting or thermoplastic resins. Thermoset resins, in the presence of a catalyst reaction or cure. Once cured these material can no longer flow. Thermosetting resins such as epoxies, bismaldeimides and cyanates can provide good strength properties. Thermoplastic resins are normally solids at room temperature but soften or melt when heated to elevated temperatures and become solid when cooled. Typical thermoplastic resins include polymide, polyamide, polyphony lene sulphide (PPS), polyether ether ketone (PEEK), polyethylene terephthalate (PET), and polyetherulfone. Thus specialty epoxy resins and curing agent designed for use in high performance composites have excellent elevated temperature resistance, good mechanical properties, low water absorption and relatively high glass transition temperature. Hence a proper combination of epoxy resin, modifying resin, reinforcing fiber, curing agent and processing procedure are required to take full advantages of their properties. Since the relatively low strength polymers can be converted into high strength composites by reinforcement, this field of the composite industry is well established and is growing faster into newer application. [1]

\section{B. Reinforcement}

The reinforcement for composites may be in the form of particles, whiskers, fibers, lamellae or a mesh. The increase the strength, stiffness or modify the failure mechanism advantageously. There can be special cases where the fibers may conduct or resist heat and 
electricity. Whiskers of metals, inter-metallic, oxides, carbides and nitrides are frequently used as reinforcement. A variety of continuous fibers of glass, carbon Kevlar (aramid), silicon carbide, alumina, boron, tungsten etc. are used as reinforcement. [1]

\section{Properties of the materials selected}

Table I. Mechanical properties of glass fibers [2]

\begin{tabular}{|c|c|c|}
\hline Properties & E-Glass & S-Glass \\
\hline Specific Gravity & 2.60 & 2.50 \\
\hline Modulus $(\mathrm{GPa})$ & 72 & 87 \\
\hline Strength $(\mathrm{MPa})$ & 3450 & 4310 \\
\hline Percentage Tensile elongation & 4.8 & 5.0 \\
\hline
\end{tabular}

Various types of glass fibers are manufactured based on the compositions. In all of the glass fibers Silica and calcium oxide play major role. The other alloy used in glass fibers are given in the table below. [2]

Table II. Composition of glass fiber [2]

\begin{tabular}{|c|c|c|}
\hline Alloy (\%) & E-Glass & S-Glass \\
\hline $\mathrm{SiO}_{2}$ & 55.2 & 65.0 \\
\hline $\mathrm{Al}_{2} \mathrm{O}_{3}$ & 8.0 & 25.0 \\
\hline $\mathrm{CaO}$ & 18.7 & - \\
\hline $\mathrm{MgO}$ & 4.6 & 10.0 \\
\hline $\mathrm{Na}_{2} \mathrm{O}$ & 0.3 & 0.3 \\
\hline $\mathrm{B}_{2} \mathrm{O}$ & 7.3 & - \\
\hline
\end{tabular}

Table III. Properties of Polypropylene

\begin{tabular}{|c|c|c|}
\hline Properties & & Polypropylene \\
\hline Specific Gravity & O & $1.35 \mathrm{~N}=?$ \\
\hline Young's modulus & (MPa) & 1800 \\
\hline Ultimate Tensile Strength & $(\mathrm{MPa})$ & 35.7 \\
\hline
\end{tabular}

\section{Details of the work to be carried out:}

$>$ To investigate the mechanical properties like ultimate tensile strength, impact strength, and hardness.

$>$ To compare the properties of E-glass and S-glass epoxy composites from obtained results.

\section{Methodology}

To fabricate Glass fiber- epoxy composite by hand layup technique. Preparation of the specimens according to the ASTM standards and investigation of the mechanical properties such as tensile strength, bending strength and hardness test .Analyzing the results obtained and checking for the optimum results by varying the stacking process of Glass-fibers or by changing the filler materials. Based on the ASTM standards the composites were made from E-glass fiber, S-glass fiber and epoxy as a resin, polypropylene used as filler materials. Fabrication of composites was done at room temperature by hand layup techniques and a composite was cured at room temperature. The proper volume fraction of fiber, epoxy, fillers and orientation of fibers are to be controlled.

\section{Hand layup technique}

Hand lay-up technique is the simplest method of composite processing. The infrastructural requirement for this method is also minimal. The processing steps are quite simple. First of all, a release gel is sprayed on the mold surface to avoid the sticking of polymer to the surface. Thin plastic sheets are used at the top and bottom of the mold plate to get good surface finish of the product. Reinforcement in the form of woven mats or chopped strand mats are cut as per the mold size and placed at the surface of mold after Perspex sheet.

Then thermosetting polymer in liquid form is mixed thoroughly in suitable proportion with a prescribed hardener (curing agent) and poured onto the surface of mat already placed in the mold. The polymer is uniformly spread with the help of brush. Second layer of mat is then placed on the polymer surface and a roller is moved with a mild pressure on the matpolymer layer to remove any air trapped as well as the excess polymer present. The process is repeated for each layer of polymer and mat, till the required layers are stacked. After placing the plastic sheet, release Gel is sprayed on the inner surface of the top mold plate which is then kept on the stacked layers and the pressure is applied.

After curing either at room temperature or at some specific temperature, mold is opened and the developed composite part is taken out and further processed. The time of curing depends on type of polymer used for composite processing. For example, for epoxy based system, normal curing time at room temperature is $24-48$ hours. This method is mainly suitable for thermosetting polymer based composites. Stacking was made in the order $1 E-2 E-1 P-3 E-2 P-4 E-$ $3 P-5 E-4 P-6 E-5 P-7 E-6 P-8 E-7 P-9 E-8 P-10 E-9 P-11 E-$ $12 E$ for GFRP (E-Glass Polypropylene).

$1 S-2 S-1 P-3 S-2 P-4 S-3 P-5 S-4 P-6 S-5 P-7 S-6 P-8 S-7 P-$

9S-8P-10S-9P-11S-12S for GFRP (S-Glass

Polypropylene).

$1 S-1 E-2 S-2 E-1 P-3 S-3 E-2 P-4 S-4 E-3 P-5 S-5 E-4 P-6 S-$ 6E-5P-7S-7E-8E-8S for GFRP (E-Glass S-Glass Polypropylene) $1 S-1 E-1 P-2 S-2 P-2 E-3 P-3 S-4 P-3 E-$ 
$5 P-6 P-4 S-7 P-4 E-8 P-5 S-9 P-5 E-10 P-6 E-6 S$

for GFRP (E-Glass S-Glass Polypropylene).

\section{Fabrication Procedure}

The S-glass, E-glass, Polypropylene/Epoxy based composites filled with varying concentrations were powered. The volume fraction of fiber, epoxy and filler materials were determined by considering the density, specific gravity and mass. The required ingredients of resins, hardener and fillers are mixed thoroughly in a basin and the mixture is subsequently stirred constantly. The glass fiber positioned manually. Mixture so made is brushed uniformly, over the glass plies and polypropylene plies. Entrapped air is removed manually with squeezes or rollers to complete the laminates structure and the composite is cured at room temperature.

Table IV. Designation and detailed composition of

\begin{tabular}{|c|c|c|c|}
\multicolumn{2}{|c|}{ the composites } \\
\hline \multirow{2}{*}{ SETS } & $\begin{array}{c}\text { \% of glass } \\
\text { Fibers by } \\
\text { volume }\end{array}$ & $\begin{array}{c}\% \text { of } \\
\text { epoxy by } \\
\text { volume }\end{array}$ & $\begin{array}{c}\% \text { of } \\
\text { filler by } \\
\text { volume }\end{array}$ \\
\hline (GFRP1)(EP) & $40 \%$ & $50 \%$ & $10 \%$ \\
\hline (GFRP2)(SP) & $40 \%$ & $50 \%$ & $10 \%$ \\
\hline
\end{tabular}

Table V. Designation and detailed composition of the

\begin{tabular}{|c|c|c|c|}
\hline \multirow{2}{*}{ SETS } & $\begin{array}{c}\text { \% of glass } \\
\text { Fibers by } \\
\text { volume }\end{array}$ & $\begin{array}{c}\% \text { of } \\
\text { epoxy by } \\
\text { volume }\end{array}$ & $\begin{array}{c}\% \text { of } \\
\text { filler by } \\
\text { volume }\end{array}$ \\
\hline (GFRP3)(ESP) & $40 \%$ & $50 \%$ & $10 \%$ \\
\hline (GFRP4)(ESP) & $30 \%$ & $50 \%$ & $20 \%$ \\
\hline
\end{tabular}

\section{Experimentation}

\section{A. Ultimate tenile test}
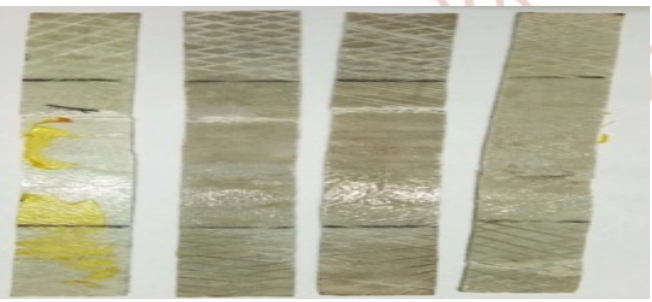

Figure I. Tensile Tested Specimen for (GFRP1) (EP)

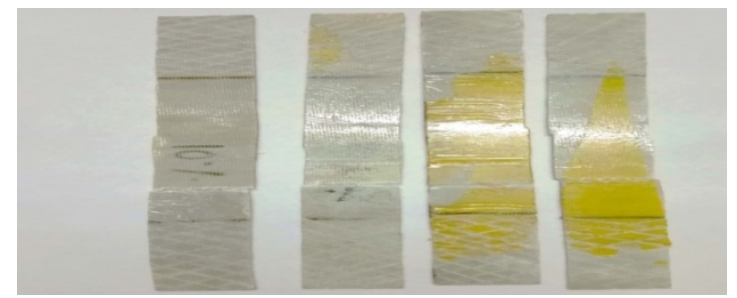

Figure II. Tensile Tested Specimen for (GFRP2) (SP)

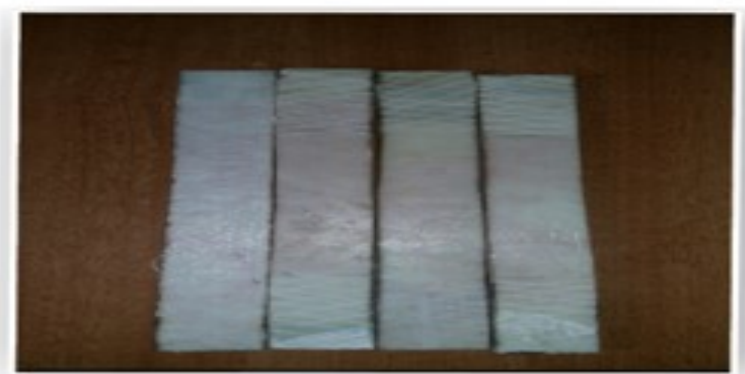

Figure III. Tensile Tested Specimen for (GFRP3) (ESP)

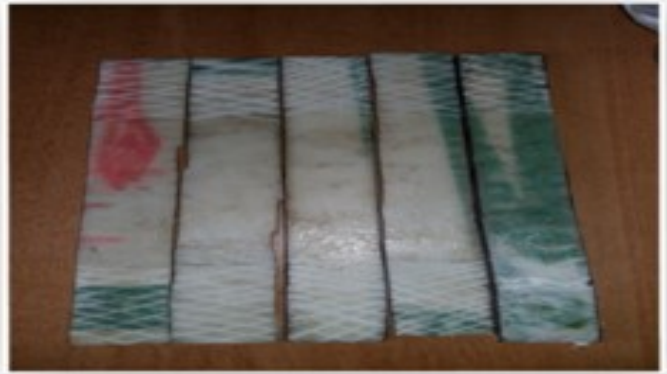

Figure IV. Tensile Tested Specimen for (GFRP4) (ESP)

B. Impact Test

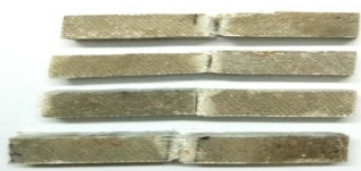

Figure V. Impact Test for (GFRP1) (EP)

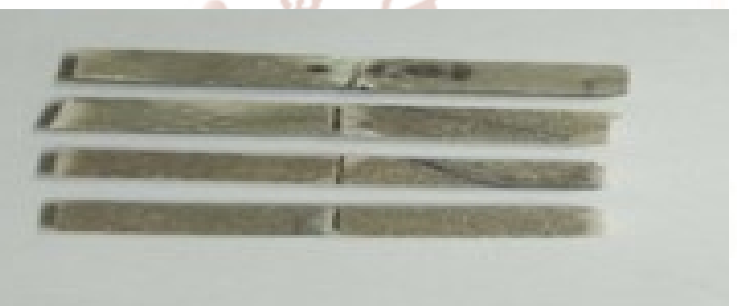

Figure VI. Impact Test for (GFRP2) (SP)

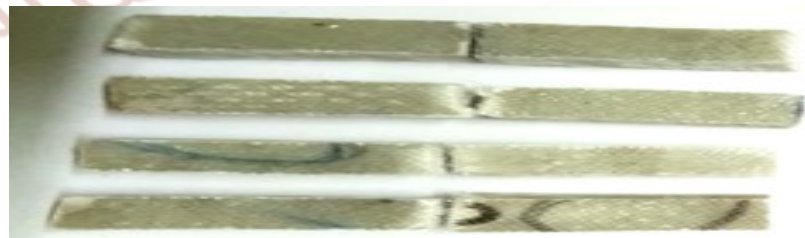

Figure VII. Impact Test for (GFRP3) (ESP)

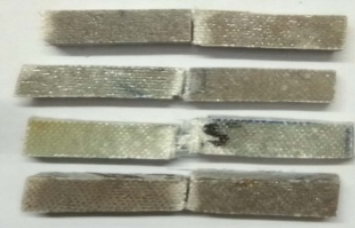

Figure VIII Impact Test for (GFRP4) (ESP) 
International Journal of Trend in Scientific Research and Development (IJTSRD) ISSN: 2456-6470

C. Brinell Hardness Test

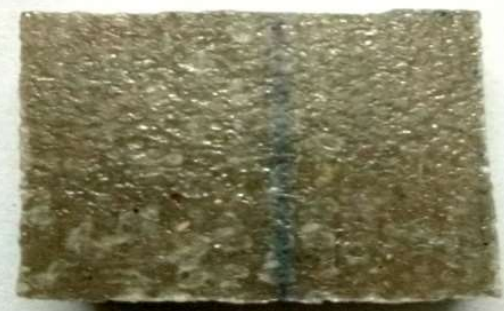

Figure IX. Brinell hardness Test for (GFRP1) (EP)

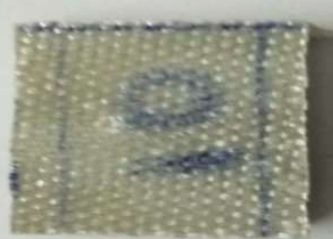

HARDNESS(BHN)

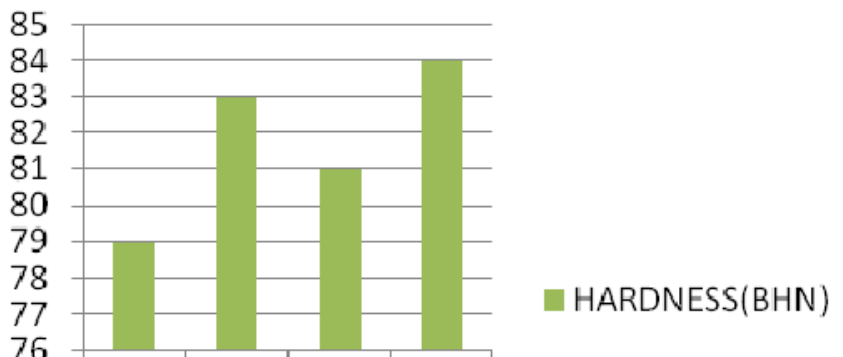

Figure X. Brinell hardness Test for (GFRP2) (SP)

Graph I. HARDNESS RESULTS COMPARISON

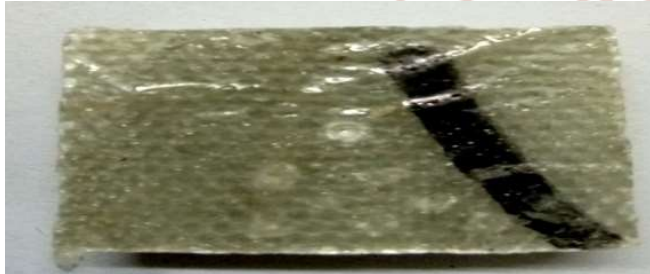

Figure XI. Brinell hardness Test for (GFRP3) (ESP)
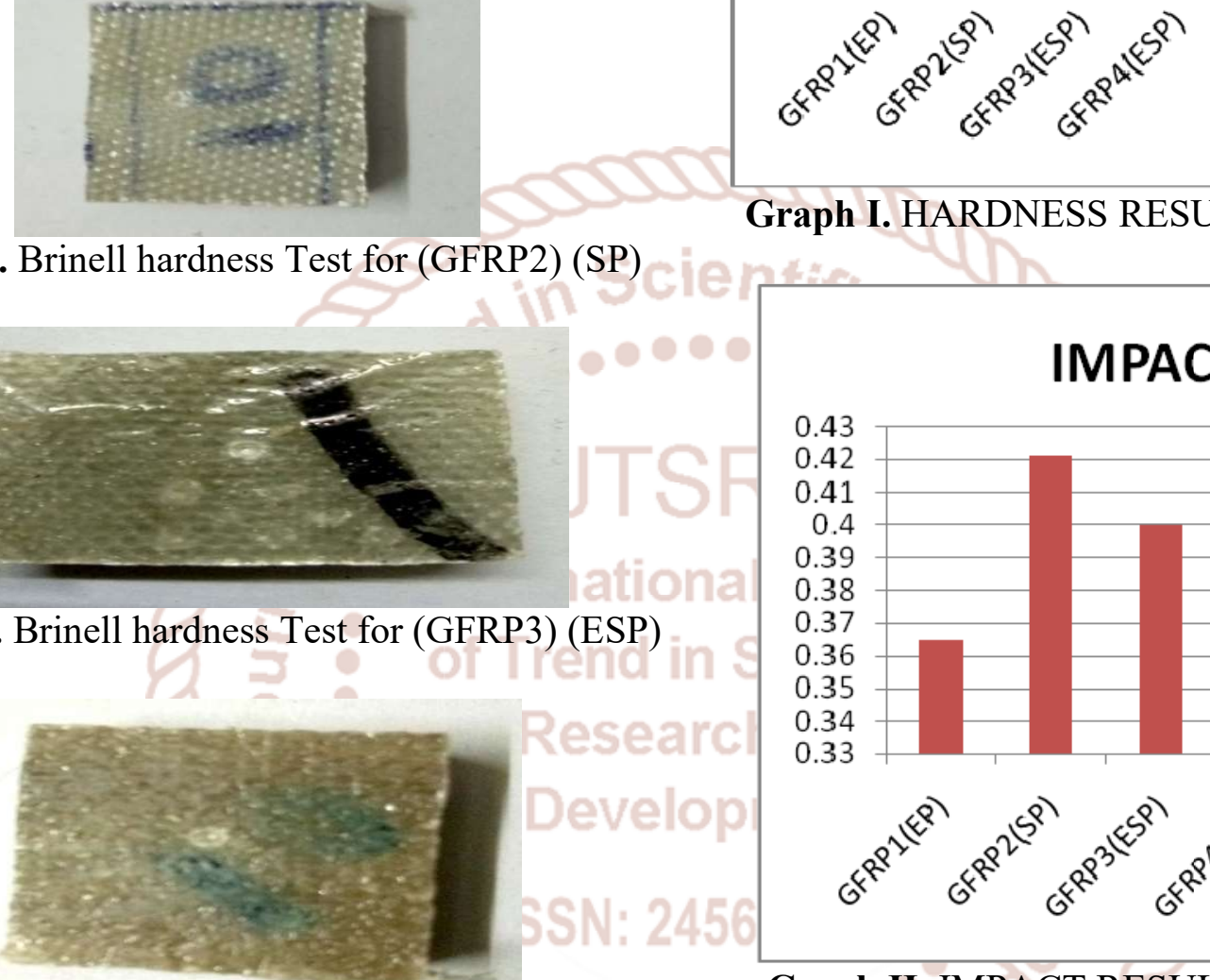

Figure XII. Brinell hardness Test for (GFRP4) (ESP)

VIII. Results

Table VI. Ultimate tensile strength (UTS), Impact and Hardness of GFRP1 and GFRP2

\begin{tabular}{|c|c|c|c|}
\hline Composites & $\begin{array}{c}\text { UTS } \\
(\text { MPA })\end{array}$ & $\begin{array}{c}\text { Impact } \\
\left(\mathrm{J} / \mathrm{mm}^{2}\right)\end{array}$ & $\begin{array}{c}\text { Hardness } \\
\text { (BHN) }\end{array}$ \\
\hline GFRP1(EP) & 178 & 0.365 & 79 \\
\hline GFRP2(SP) & 240.23 & 0.421 & 83 \\
\hline
\end{tabular}

Table VII. Ultimate tensile strength (UTS), Impact and Hardness of GFRP3 and GFRP4

\begin{tabular}{|c|c|c|c|}
\hline Composites & $\begin{array}{c}\text { UTS } \\
\text { (MPA) }\end{array}$ & $\begin{array}{c}\text { Impact } \\
(\mathrm{J} / \mathrm{mm} 2)\end{array}$ & $\begin{array}{c}\text { Hardiness } \\
\text { (BHN) }\end{array}$ \\
\hline GFRP3(ESP) & 233.6 & 0.40 & 81 \\
\hline GFRP4(ESP) & 186 & 0.384 & 84 \\
\hline
\end{tabular}

Graph II. IMPACT RESULTS COMPARISON

\section{IMPACT(J/mm²)}
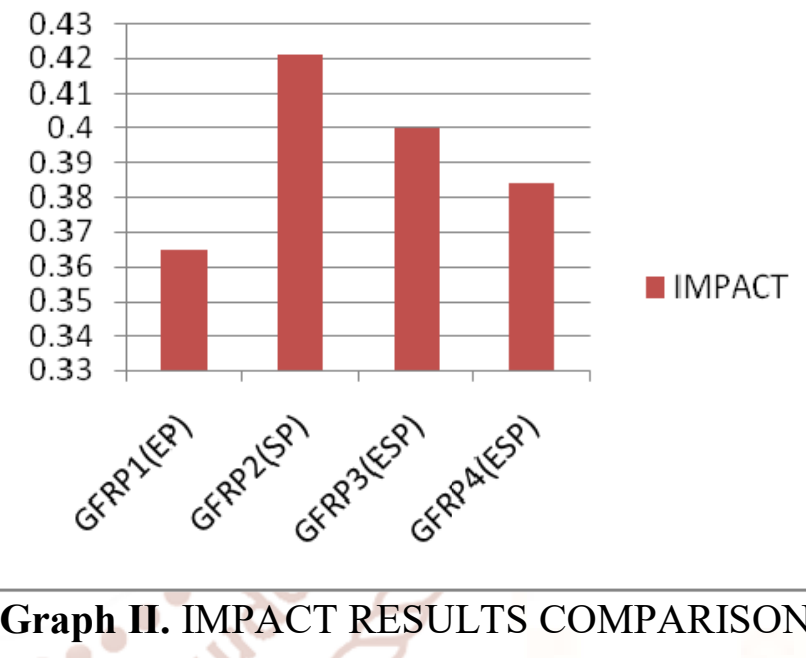

\section{UTS(MPA)}

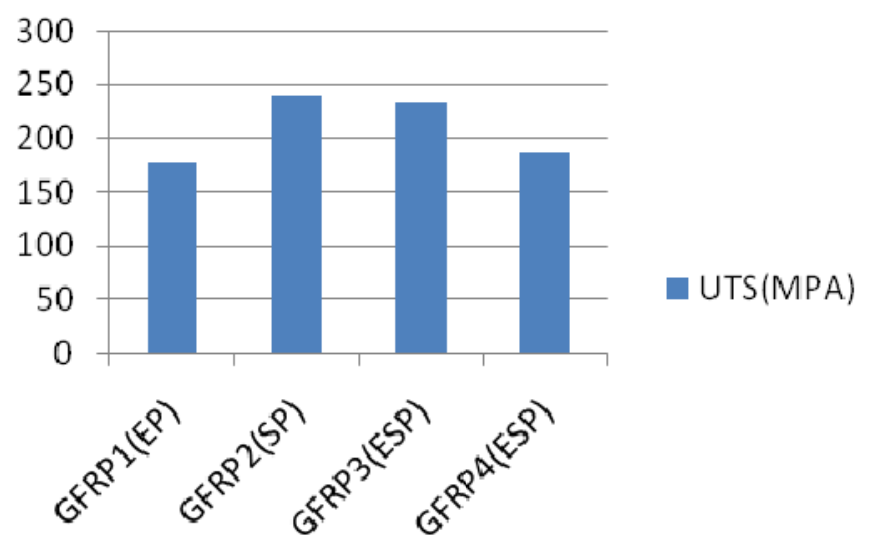

Graph III. UTS RESULTS COMPARISON 


\section{Discussions}

The experimental study on the effect of fiber and filler loading on mechanical behavior of GFRP composites leads to the following;

$>$ The present investigation reveals that fiber and filler loading significantly effect on the different properties of composites.

$>$ The experimental result reveals that the composite GFRP1 and GFRP2 show better tensile strength properties.

$>$ The hardness of the composites increased with increase in filler loading.

$>$ The Impact strength of the composite reduced with increases in filler material. This implies that right percentage of filler material is required for good Impact strength.

$>$ The balancing of tensile strength and Impact strength is possible by right proportions of fibers and filler materials used.

\section{REFERENCES}

1. M. Somaiah Chowdary, M. S. R Niranjan Kumar, Effect of Nanoclay on the Mechanical properties of Polyester and S-Glass Fiber (Al), International Journal of Advanced Science and Technology,Vol.74 (2015), pp.35-42.

2. S. Pichi Reddy, P. V. Chandra Sekhar Rao, A. Chennakesava Reddy, G. Parmeswari, Tensile And Flexural Strength Of Glass Fiber Epoxy Composites, International Conference on Advanced Materials and manufacturing Technologies (AMMT), Paramount Publishing House, Hyderabad, December 18-20, 2014.

3. S. Sivasaravanan., V. K. Bupesh Raja, Impact Properties Of Epoxy/Glass Fiber/Nano Clay Composite Materials, IOSR Journal of Mechanical and Civil Engineering (IOSR-JMCE) e- ISSN: 2278-1684, p-ISSN : 2320-334X PP 3941.

4. K. Devendra, T. Rangaswamy, Strength Characterization of E-glass Fiber Reinforced Epoxy Composites with Filler Materials, Journal of Minerals and Materials Characterization and Engineering, 2013, 1,pp. 353-357.
5. K. Devendra and T. Rangaswamy, Thermal Conductivity and Thermal Expansion Coefficient of GFRP Composite Laminates with Fillers, Mechanica Confab, ISSN: 2320-2491, Vol. 2, No. 5, August-September 2013.

6. K. Devendra and T. Rangaswamy, Determination Of Mechanical Properties $\mathrm{OfAl}_{2} \mathrm{O}_{3}, \mathrm{Mg}(\mathrm{OH})_{2}$ And Sic Filled E-Glass/ Epoxy Composites, International Journal of Engineering Research and Applications ISSN: 2248-9622, Vol. 2, Issue 5, September- October 2012, pp.2028-2033

7. K. Devendra and T. Rangaswamy, Evaluation of Thermal Properties of E-Glass/ Epoxy Composites Filled by Different Filler Materials, International Journal Of Computational Engineering Research (ijceronline.com) Vol. 2 Issue.5,September2012,pp.1708-1714

8. K.M. Kelvin Loh and C.K. Willy Tan, Natural Silkworm Silk-Epoxy Resin Composite for High Performance Application ,Metal, Ceramic and Polymeric Composites for Various Uses, ISBN 978-953-307-353-8,pp.326-340

9. C. Elanchezhian, B. Vijaya Ramnath, M. U. Süghan, K. Suseetharan V. Varun Kumar, R. Vezhavendan and R. Kaosik, Evaluation of mechanical properties of human hair-bombyx mori silk fiber reinforced epoxy based Biocomposite, ARPN Journal of Engineering and Applied Sciences, ISSN 1819-6608,pp.5498-5505

10. P. Ramesh, J. Ayyamperum, P. Boopathi, V. M. Gokulakannan, Analysis of Mechanical Properties of Silk/Flax Hybrid Epoxy Composite Material, International Journal of Innovative Research in Science, Engineering and Technology, ISSN(Online) : 2319 - 8753,pp.1656-1662.

11. U. S. Bongarde, V. D. Shinde, Review on natural fiber reinforcement polymer composites, International Journal of Engineering Science and Innovative Technology (IJESIT)Volume 3, Issue 2, March 2014, ISSN :2319-5967,pp.431-436. 